Research Article

\title{
Prevalence, Awareness, Treatment, and Control and Related Factors of Hypertension in Multiethnic Agriculture, Stock-Raising, and Urban Xinjiang, Northwest China: A Cross-Sectional Screening for 47000 Adults
}

\author{
Lin Wang, Nanfang Li $(\mathbb{D}$, Mulalibieke Heizhati, Xiaoguang Yao, Gulinuer Duiyimuhan, \\ Keming Zhou, Mei Cao, Menghui Wang, Junli Hu, and Delian Zhang \\ Hypertension Center of People's Hospital of Xinjiang Uygur Autonomous Region, Hypertension Institute of Xinjiang, \\ Urumqi 830001, Xinjiang, China \\ Correspondence should be addressed to Nanfang Li; lnanfang2016@sina.com
}

Received 21 April 2019; Accepted 6 September 2019; Published 3 November 2019

Academic Editor: Tomohiro Katsuya

Copyright (c) 2019 Lin Wang et al. This is an open access article distributed under the Creative Commons Attribution License, which permits unrestricted use, distribution, and reproduction in any medium, provided the original work is properly cited.

\begin{abstract}
Background. Hypertension is the leading cause of cardiovascular disease. Distribution of hypertension and related factors among multiethnic population in Northwest China remains scarce. The aim was to determine prevalence, awareness, treatment, control, and risk factors associated with hypertension among multiethnic population in Northwest China. Methods. We conducted a blood pressure (BP) screening project covering a third of adults in Emin Xinjiang, Northwest China, during 2014-2016. Hypertension was defined as systolic $\mathrm{BP} \geq 140 \mathrm{mmHg}$, diastolic $\mathrm{BP} \geq 90 \mathrm{mmHg}$, and/or taking antihypertension drugs. We compared prevalence, awareness, treatment, and control of hypertension and related factors by different regions (agriculture, stock-raising, or urban) and by ethnic groups. Results. Totally 47,040 adults were screened with $48.5 \%$ women. Overall prevalence, awareness, treatment, and control of hypertension were $26.5 \%, 64.6 \%, 44.5 \%$, and $15.3 \%$, respectively. Age-gender-adjusted hypertension prevalence was higher in urban (28.2\%) than in other regions and in Kazakh (30.3\%) than in others. The lowest awareness and treatment rates were observed in the agricultural region and in Kazakh subjects, while the lowest control was in the stock-raising region (13.8\%) and in Kazakh subjects (12.6\%). After adjusting for age, gender, ethnicity, and regions, compared to normal weight, nonsmokers, and nondrinkers, obesity, smoking, and alcohol intake were significantly related to increased prevalence of hypertension by 94\%, 1.5, and 3.9 folds, respectively. Conclusions. Disparities in hypertension control among regions and ethnic groups suggested inadequate screening and treatment, especially in stock-raising regions and Kazakh populations. Control of alcohol intake, smoking, and obesity should be at high priority of health promotion.
\end{abstract}

\section{Introduction}

Globally, cardiovascular disease (CVD) including stroke leads to 17 million deaths each year, of which $80 \%$ occurs in low- or middle-income countries such as China $[1,2]$. Based on nationwide data in 2013-2014, the age-standardized prevalence, incidence, and mortality rates for stroke were $1114.8,246.8$, and 114.8 per 100,000 population in China [3]. Furthermore, in some regions such as Xinjiang, these rates are even higher $(1176.4,316.2$, and 138.5 per 100,000 population) [3]. Over $70 \%$ of the stroke burden can be attributed to hypertension in China [2], and over $80 \%$ of stroke survivors in northwest regions encompassing Xinjiang are reported to have hypertension [4]. As the leading risk factor of CVD, hypertension is highly prevalent in Xinjiang, affecting $35.01 \%$ of adults aged $\geq 35$ years and $40.7 \%$ of those $\geq 45$ years $[5,6]$.

Xinjiang, a relatively undeveloped province with a multiethnic and multicultural population, is one of the four stock-raising areas (accounting for $34.68 \%$ of the total land) in China and is bordered with Central Asian countries. Onefifth of local residents are leading nomadic or seminomadic 
lives, making the access of fresh vegetables and fruits difficult, the penetration rate of medical resources low, and poor health awareness poor [7]. All these factors may lead to a higher prevalence of hypertension and its poor management especially among residents in the stock-raising region. Nonetheless, information about the prevalence, awareness, treatment, and control rates and the contributing factors of hypertension in the stock-raising region is limited. It is well known that hypertension is a complex interaction of multiple genetic, environmental, and behavioral factors $[8,9]$. The timely exploration of the magnitude and management of hypertension is fundamental.

Therefore, this study aimed to explore the regional and ethnic disparities in hypertension status and to in-depth analyze potential variations in prevalence, awareness, treatment, and control of hypertension and associated factors. Thereby, the results may provide basis for the design and implementation of appropriate interventions for hypertension in the Xinjiang area extending to the Central Asian countries with the same ethnicity and approximate conditions.

\section{Materials and Methods}

2.1. Study Population. All the participants were selected from the hypertension screening project which included health archives, health check-up records, and disease registrations with a solid information security system from 1 Jan 2014 to 31 Dec 2016 in Emin, Xinjiang. Emin is one of the counties with a larger population base in Xinjiang, including 4 towns, 7 townships, and 6 stock-raising regions. There are 25 ethnic groups with four main groups such as Han, Kazakh, Uygur, and Mongolian, and with a total population of over 160,000 . Of them, population aged $\geq 15$ accounts for $83.36 \%$. In addition, Han and Uygur residents mainly live in the urban and agricultural setting, while Kazakh and Mongolian residents in the stock-raising setting.

2.2. Data Collection. A community-based door-to-door screening for the health behavior questionnaire and anthropometric examination were conducted. Eligible population included residents aged $\geq 15$ years and living $\geq 6$ months. A unified questionnaire was taken including questions on demographics, educational status, cigarette consumption, alcohol intake, and hypertension-related information (Whether it was previously diagnosed by a doctor? Whether it has been being treated? Whether he/she is taking antihypertensive drugs within the previous two weeks?). The Hypertension Center of the People's Hospital of Xinjiang Uygur Autonomous Region designed the survey, and it was approved by the Ethics Committee of the abovementioned hospital. Informed consent was obtained from all participants. Participant's anonymity was accomplished by using a nontraceable ID-number. Anthropometric variables were measured using standard equipment and procedures.

The blood pressure (BP) values of the individuals were obtained with three measurements taken after resting for at least $5 \mathrm{~min}$. Participants were advised to avoid smoking, caffeinated drinks, alcohol, and exercise for at least $30 \mathrm{~min}$ before measurement. Measurement was taken from the unclothed right arm of the person in a sitting position.

Systolic BP (SBP) and diastolic blood pressure (DBP) were measured using an Omron HEM-1300 electronic monitor. Height was measured without shoes using a standard right-angle device and a fixed measurement tape (to the nearest $0.1 \mathrm{~cm}$ ). Body weight without heavy clothing was measured using a weight measurement device (V-body HBF-371.7, OMRON, Kyoto, Japan). Waistline circumference (WC) was measured in the midpoint between the lower rib and upper margin of the iliac crest, measured by a ruler tape with an insertion buckle at one end. WC was measured to the nearest $0.1 \mathrm{~cm}$.

All study investigators and staff members including physicians, nurses, health care providers, and general practitioners were trained to be familiar with both the aims of the study and the specific tools and methods used.

2.3. Definitions. Hypertension (HT) was defined as having an SBP of $\geq 140 \mathrm{~mm} \mathrm{Hg}$ and/or DBP of $\geq 90 \mathrm{~mm} \mathrm{Hg}$, or if the individual was on antihypertensive medication. Awareness was defined as whether they had a medical diagnosis of hypertension and treatment as whether they were receiving BP-lowering medications. Control was defined as an average SBP and DBP $<140 / 90 \mathrm{mmHg}$.

Regarding education, participants were categorized into three levels: low education: primary and lower; middle: junior and senior high; and high: college and higher. Marital status was coded as single, married, or widow/divorced; occupational status as agriculture and stock-raising and nonagriculture and non-stock-raising; alcohol intake as current drinker (drinker was defined as consuming alcoholic beverage at least once per week in the past month) and nondrinker [10]; and cigarette consumption as current smoker (smokers were defined as participants who have smoked at least 20 packets of cigarettes in their lifetime and currently smoke cigarettes) and nonsmokers (participants who never smoked or smoked $<20$ packets of cigarettes in their entire lifetime) [10]. Body mass index (BMI) was calculated by dividing weight (in kilograms) by height (in meters) squared $\left(\mathrm{kg} / \mathrm{m}^{2}\right)$. To ensure comparability with other studies, our study incorporated the criteria recommended by the Working Group on Obesity in China (normal: BMI < $24.0 \mathrm{~kg} / \mathrm{m}^{2}$; overweight: BMI $24.0-28.0 \mathrm{~kg} /$ $\mathrm{m}^{2}$; general obesity: $\mathrm{BMI} \geq 28 \mathrm{~kg} / \mathrm{m}^{2}$; and abdominal obesity: $\mathrm{WC}>90 \mathrm{~cm}$ for men and $>85 \mathrm{~cm}$ for women) and the WHO classifications for European (normal: BMI $<25.0 \mathrm{~kg} / \mathrm{m}^{2}$; overweight: BMI $25.0-30.0 \mathrm{~kg} / \mathrm{m}^{2}$; general obesity: BMI $>30 \mathrm{~kg} / \mathrm{m}^{2}$; and abdominal obesity: $\mathrm{WC}>102 \mathrm{~cm}$ for men and $>88 \mathrm{~cm}$ for women). Urban and rural was divided according to the National Bureau of Statistics of the People's Republic of China published on the urban and rural regional code, the division of agricultural and stock-raising settings in accordance with the region's main source of economic income to distinguish [11].

2.4. Statistical Analysis. Data analysis was made for the overall study population by region and ethnicity. To enable 
comparisons between subgroups, results were adjusted by age and sex. Continuous variables were presented as mean (SD) deviations and were analyzed using ANOVA. Categorical variables were expressed as frequency $(n)$ and proportion (\%) and were analyzed using the Chi-square test. As for hypertension, multivariable logistic analysis was used to analyze the associated factors for prevalence, awareness, treatment, and control of hypertension; adjusted odds ratio (OR) with associated $95 \%$ confidence interval (95\% CI) were calculated. For each dependent variable, the independent variables included in the multivariable logistic model were mainly the variables with statistical significance in the univariable analysis, which is set as $p$ values $\leq 0.10$. All statistical tests were two-tailed, and differences were considered statistically significant when the $p$ value was $<0.05$. All statistical analyses were performed using SPSS 19.0 for Windows.

\section{Results}

3.1. Demographic Characteristics of Participants. During door-to-door visit, 59405 subjects aged $\geq 15$ years were invited for screening, of whom 49497 subjects (83.3\% response rate) agreed, covering one third (34.5\%, 49497/143289) of adult residents. 47040 subjects with complete data (2457 subjects were excluded; 1135 aged $<18$ years and 1322 with incomplete data) were analyzed with overall $48.5 \%$ women subjects (Figure 1). A total of $54.9 \%$ participants $(n=25850$; aged 43.6 years) were enrolled from the agricultural setting, $17.0 \%$ ( $n=7994$; aged 42.0 years) from the stock-raising setting, and $28.1 \%(n=13196$; aged 45.9 years $)$ were from the urban setting. Subjects from the urban setting were older than those from the stock-raising and agricultural settings. $77.4 \%$ subjects in the stock-raising setting were Kazakh ethnicity, and $53.4 \%$ in the urban setting were Han ethnicity; $43.3 \%$ in the agricultural setting were Han and $45.5 \%$ were Kazakh ethnicity. Subjects from the urban setting had significantly higher SBP than in those from the agricultural and stock-raising settings (Table 1).

3.2. Prevalence of Hypertension. Overall, $26.5 \%$ of participants aged $\geq 18$ years $(25.2 \%$ of men vs. $27.9 \%$ of women; $p<0.001)$ had hypertension. There were significant differences in age- and sex-standardized hypertension status for each subgroup $(p<0.001)$ (Table 2$)$. The age- and sexstandardized prevalence of hypertension is $25.4 \%$ in the agricultural setting, $27.2 \%$ in the stock-raising setting, and $28.2 \%$ in the urban setting. The prevalence of hypertension increased with aging in both sex and in agricultural, stockraising, and urban settings $(p<0.001)$. Kazakh subjects showed higher prevalence rate of hypertension than other ethnic groups $(30.3 \%$ for Kazakh, 23.2\% for Han, $28.8 \%$ for Uygur, and $27.8 \%$ for Mongolian).

3.3. Awareness, Treatment, and Control of Hypertension. Among those with hypertension, 64.6\% (95\% CI, 61.9\%$67.1 \%)$ were aware of their condition and $44.5 \%(95 \% \mathrm{CI}$, $43.7 \%-45.2 \%)$ were taking medications to lower their BP, whereas only $15.3 \%$ (95\% CI, $14.8 \%-15.9 \%)$ achieved BP control (Table 2).

The awareness, treatment, and control rates of hypertension were higher among women than men $(67.1 \%$ vs. $61.9 \%, 47.8 \%$ vs. $41.2 \%$, and $16.1 \%$ vs. $14.4 \%$, respectively, $p$ for all $<0.001)$. The awareness and treatment rates were lower in patients from agricultural regions than in those from urban or stock-raising settings (awareness rate: $59.7 \%$ vs. $66.5 \%$ vs. $76.3 \%$; treatment rate: $41.6 \%$ vs. $42.3 \%$ vs. $58.4 \%$ ), whereas the control rate in patients from the stock-raising setting was lower than that of those from the urban and agricultural setting (13.8\% vs. $15.2 \%$ vs. $15.8 \%, p<0.05)$. The awareness, treatment, and control rates of hypertension were lower in Kazakh subjects than in other ethnic groups ( $p$ for all $<0.001$ ). The treatment was higher in participants with low education $(p=0.022)$, whereas the control rate was lower (Table 2).

3.4. Multivariable Risk Assessment. After adjusting for age, gender, ethnicity, and regions, abdominal obesity (OR 1.30; 95\% CI, 1.21-1.41), general obesity (OR 1.94; 95\% CI, 1.75-2.15), cigarette consumption (OR 2.49; 95\% CI, 2.202.81), and alcohol intake (OR 4.90; 95\% CI, 4.33-5.53) were significantly associated with the presence of hypertension $(p<0.05)$ (Table 3, Supplementary Figure 2). Male gender and abdominal obesity were associated with lower awareness and treatment. Kazakh subjects, nonagricultural, and nonstock-raising occupation and lower education attainment were significantly associated with lower control of hypertension $(p<0.05)$ (Table 3, Supplementary Figures 3-5).

\section{Discussion}

This study, to the best of our knowledge, was one of the largest hypertension screening project, seeking to explore the disparities in prevalence and management of hypertension in adult population from urban, agricultural, and stock-raising regions in Xinjiang, Northwest China. This study extended previous evidence to local agricultural and stock-raising settings that signify the current burden and status of hypertension in these specific settings. Main results encompassed that approximately $26.5 \%$ of residents aged $\geq 18$ years in Xinjiang have hypertension, higher than the $23.1 \%$ of national average [10]. Hypertension treatment and control rates are approximate to the national average (treatment rate: $44.5 \%$ vs. $40.7 \%$; control rate: $15.3 \%$ vs. $15.3 \%$ ), whereas the gaps still exist between these rates and those of developed countries $[12,13]$.

Hypertension is the leading modifiable risk factor for CVD and stroke $[1,2]$. However, no region and ethnicity in the current study has an overall control rate over $20 \%$, which demonstrates that efforts to expand access to and improve the effectiveness of hypertension management are needed among multiethnic population in Northwest China. The strategies used, however, may vary with respect to the underlying regional and ethnic patterns revealed in this study. For example, our analysis showed the highest prevalence of hypertension in urban and stock-raising regions and in Kazakh and Uygur population and the lowest control rate in the stock-raising region and Kazakh. Thus, developing and 


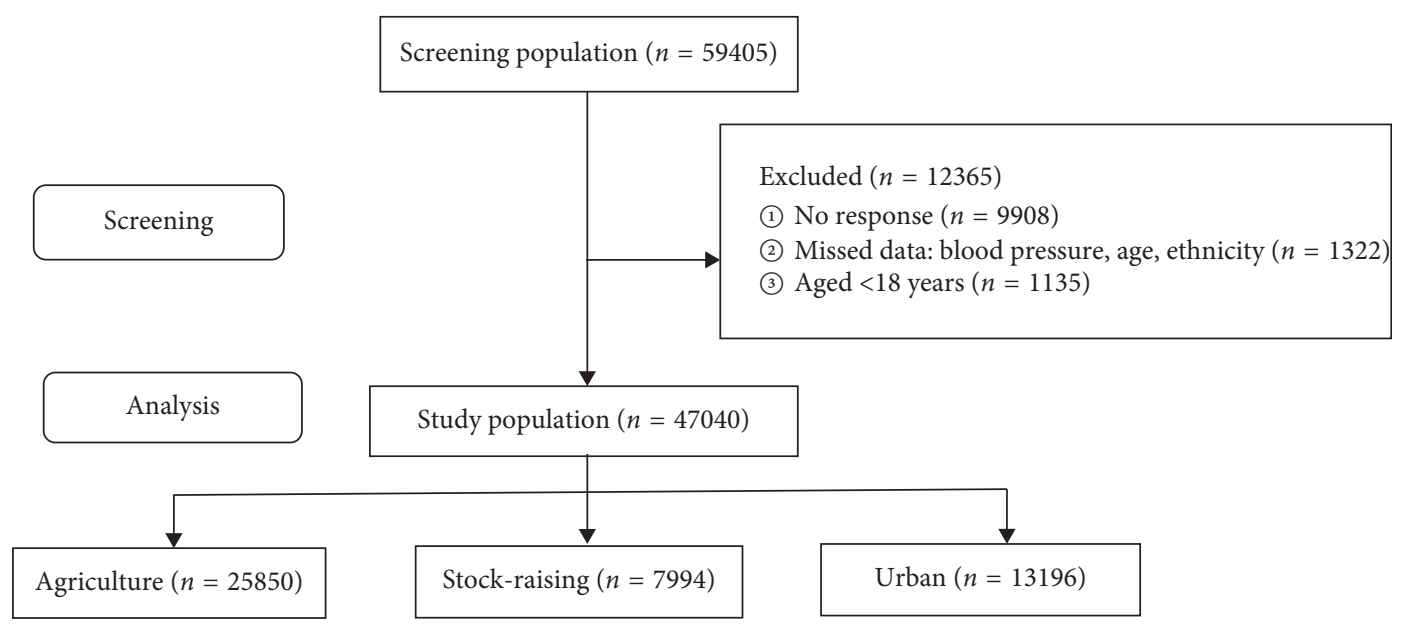

FIGURE 1: The process of recruiting the surveyed subjects including screening and analysis. 12,365 participants excluded due to missing data.

TABLE 1: Baseline characteristics of the study population by region and sex.

\begin{tabular}{|c|c|c|c|c|c|c|}
\hline \multirow{2}{*}{ Characteristic } & \multicolumn{3}{|c|}{ Regions } & \multicolumn{2}{|c|}{ Sex } & \multirow{2}{*}{ Total } \\
\hline & Agriculture & Stock-raising & Urban & Men & Women & \\
\hline Subjects, $n(\%)$ & $25850(55.0)$ & $7994(17)$ & $13196(28.1)$ & $24229(51.5)$ & $22811(48.5)$ & $47040(100)$ \\
\hline Age (years) & $43.6(15.3)$ & $42.0(15.1)$ & $45.9(15.4)^{\mathrm{b}}$ & $43.6(15.3)$ & $44.4(15.4)$ & $44.0(15.3)$ \\
\hline BMI, kg/m², mean (SD) & $24.6(3.4)$ & $24.3(3.5)$ & $24.7(3.5)^{\mathrm{b}}$ & $25.0(3.3)$ & $24.1(3.6)$ & $24.5(3.4)$ \\
\hline $\mathrm{WC}, \mathrm{cm}$, mean $(\mathrm{SD})$ & $90.2(13.0)$ & $89.6(13.7)$ & $90.5(13.4)$ & $92.0(12.7)$ & $88.2(13.7)$ & $90.2(13.4)$ \\
\hline Cigarette smoking, $n(\%)$ & $4376(16.9)$ & $1430(17.9)$ & $2409(18.3)$ & $8063(33.3)$ & $152(0.7)$ & 8215 (17.5) \\
\hline Alcohol drinking, $n(\%)$ & $3827(14.8)$ & $1439(18.0)$ & $2216(16.8)$ & $7376(30.4)$ & $106(0.5)$ & $7482(15.9)$ \\
\hline \multicolumn{7}{|l|}{ Education status, $n(\%)$} \\
\hline Primary and lower & $10631(41.8)$ & $2139(26.9)$ & $2080(40.5)$ & $7457(36.9)$ & $7393(40.4)$ & $14850(38.6)$ \\
\hline Elementary middle school & $12127(46.7)$ & $5357(67.3)$ & $2428(47.3)$ & $10869(53.8)$ & $9043(49.4)$ & $19912(51.7)$ \\
\hline High school or above & $2648(10.4)$ & $464(5.8)$ & $627(12.2)$ & $1866(9.3)$ & $1873(10.2)$ & $3739(9.7)$ \\
\hline \multicolumn{7}{|l|}{ Marital status, $n(\%)$} \\
\hline Single & $3633(14.1)$ & $968(12.1)$ & $1487(11.3)$ & $3525(14.5)$ & $2563(11.2)$ & $6088(12.9)$ \\
\hline Married & $21276(82.3)$ & $6927(86.7)$ & $11278(85.5)$ & $20197(83.4)$ & $19284(84.5)$ & $39481(83.9)$ \\
\hline Divorced & $941(3.6)$ & $99(1.2)$ & $431(3.3)^{\mathrm{b}}$ & $507(2.1)$ & $964(4.3)$ & $1471(3.2)$ \\
\hline \multicolumn{7}{|l|}{ Occupation, $n(\%)$} \\
\hline Agricultural and husbandry & $22466(86.9)$ & $6549(91.9)$ & $4317(32.7)$ & $17637(72.8)$ & $15695(68.8)$ & $33332(70.9)$ \\
\hline Nonagriculture or husbandry & $3383(13.1)$ & $1445(18.1)$ & $8879(67.3)$ & $6591(27.2)$ & $7116(31.2)$ & $13707(29.1)$ \\
\hline \multicolumn{7}{|l|}{ Ethnicity, $n(\%)$} \\
\hline Han & $11182(43.3)$ & $956(12.0)$ & $7042(53.4)$ & $9934(41.0)$ & $9246(40.5)$ & $19180(40.8)$ \\
\hline Kazakh & $11767(45.5)$ & $6184(77.4)$ & $4160(31.5)$ & $11452(47.3)$ & $10659(46.7)$ & $22111(47.0)$ \\
\hline Uygur & $628(2.4)$ & $112(1.4)$ & $1087(8.2)$ & $873(3.6)$ & $954(4.2)$ & $1827(3.9)$ \\
\hline Mongolian & $1067(4.1)$ & $585(7.3)$ & $537(4.1)$ & $1049(4.3)$ & $1140(5.1)$ & $2189(4.7)$ \\
\hline Other & $1206(4.7)$ & $157(2.0)$ & $370(2.8)$ & $921(3.8)$ & $812(3.6)$ & $1733(3.7)$ \\
\hline SBP, mmHg, mean (SD) & $120.8(16.0)$ & $120.5(17.3)$ & $124.8(17.6)^{\mathrm{b}}$ & $122.9(15.7)$ & $120.8(17.7)$ & $121.9(16.8)$ \\
\hline DBP, mmHg, mean (SD) & $76.4(9.4)$ & $76.4(10.0)$ & $76.5(10.3)$ & $77.3(9.4)$ & $75.5(10.1)$ & $76.5(9.8)$ \\
\hline
\end{tabular}

BMI: body mass index; DBP, diastolic blood pressure; SBP, systolic blood pressure; SD, standard deviation; WC, waist circumference; $p$ values for interaction comparing groups in regions: $:^{\mathrm{a}}<0.05 ;{ }^{\mathrm{b}}<0.0001$. Regions: agriculture, stock-raising, and urban.

practicing prioritized means of control for hypertension in these regions and ethnic groups are warranted.

Earlier epidemiological surveys reported large urbanrural gradients in Xinjiang, with lower prevalence of hypertension and lower rates of treatment and control in rural residents [14]. Currently, our study suggests that this gradient still exists locally. Nonetheless, this study further observes that the prevalence of hypertension is higher in stock-raising regions than agricultural regions, but with lower rates of control of hypertension in the stock-raising region compared with the agricultural setting. Background reasons may include the following: (1) Common antihypertensive agents are not readily available in many stockraising regions. Furthermore, a large proportion of individuals could not afford, based on their household income, even if there are available agents in the stock-raising region $[15,16]$. It also widely exists that hypertensive individuals often stop taking agents when BP control was achieved, 
TABLE 2: Prevalence of hypertension and proportions who were aware, treated, and controlled in the study population.

\begin{tabular}{|c|c|c|c|c|c|}
\hline & & $\begin{array}{c}\text { Prevalence (\%) }(95 \% \\
\text { CI) }\end{array}$ & $\begin{array}{c}\text { Awareness (\%) (95\% } \\
\text { CI) }\end{array}$ & $\begin{array}{c}\text { Treatment (\%) }(95 \% \\
\text { CI) }\end{array}$ & $\begin{array}{c}\text { Control (\%) }(95 \% \\
\text { CI) }\end{array}$ \\
\hline \multirow{2}{*}{ Sex } & Women & $27.9(24.5-30.3)$ & $67.1(64.3-69.8)$ & $47.8(44.3-49.5)$ & $16.1(14.3-18.7)$ \\
\hline & Men & $25.2(23.3-28.1)$ & $61.9(58.2-64.2)$ & $41.2(38.7-43.7)$ & $14.4(12.2-16.5)$ \\
\hline \multirow{6}{*}{ Age } & $18-24$ & $1.7(0.9-2.1)$ & $6.3(4.5-8.2)$ & - & - \\
\hline & $25-34$ & $3.5(1.2-8.0)$ & $21.6(19.7-24.2)$ & $6.9(4.2-9.7)$ & $2.3(0.8-4.6)$ \\
\hline & $35-44$ & $16.6(12.4-19.8)$ & $31.9(29.3-34.4)$ & $16.3(13.4-19.8)$ & $5.3(3.1-7.6)$ \\
\hline & $45-54$ & $33.9(29.1-37.4)$ & $58.1(54.6-62.1)$ & $38.0(35.2-40.6)$ & $12.7(9.2-15.1)$ \\
\hline & $55-64$ & $53.2(49.1-58.2)$ & $74.2(70.4-77.9)$ & $52.2(49.6-55.9)$ & $18.1(15.6-21.4)$ \\
\hline & $\geq 65$ & $66.3(62.3-70.1)$ & $84.8(80.9-87.4)$ & $63.6(60.1-66.9)$ & $22.2(18.8-25.9)$ \\
\hline \multirow{3}{*}{ Regions } & Agriculture & $25.4(23.6-27.1)$ & $59.7(57.1-61.6)$ & $41.6(39.9-43.2)$ & $15.8(14.1-17.4)$ \\
\hline & Stock-raising & $27.2(25.3-29.0)$ & $76.3(74.5-78.1)$ & $58.4(56.8-60.1)$ & $13.9(12.2-15.7)$ \\
\hline & Urban & $28.2(26.4-30.2)$ & $66.5(64.8-68.2)$ & $42.3(40.5-44.0)$ & $15.4(13.8-17.2)$ \\
\hline \multirow{5}{*}{ Ethnicity } & Han & $23.2(21.8-24.6)$ & $66.5(65.1-67.9)$ & $47.0(45.5-48.4)$ & $17.5(16.1-19.0)$ \\
\hline & Kazakh & $30.3(28.9-32.7)$ & $62.3(60.9-64.8)$ & $41.5(38.9-44.1)$ & $12.6(10.2-15.1)$ \\
\hline & Uygur & $28.8(26.4-31.2)$ & $70.4(67.0-73.9)$ & $44.8(42.3-47.2)$ & $19.9(17.5-22.3)$ \\
\hline & Mongolian & $27.8(25.4-30.2)$ & $65.3(63.0-67.8)$ & $45.1(42.7-47.5)$ & $14.8(12.3-17.2)$ \\
\hline & Others & $23.0(21.6-24.4)$ & $59.8(57.4-62.2)$ & $45.4(43.9-47.8)$ & $22.8(20.2-25.3)$ \\
\hline \multirow{3}{*}{$\begin{array}{l}\text { Education } \\
\text { status }\end{array}$} & Primary and lower & $29.0(26.6-32.5)$ & $61.5(58.7-64.3)$ & $43.7(40.9-45.3)$ & $13.6(11.2-15.9)$ \\
\hline & $\begin{array}{c}\text { Elementary middle } \\
\text { school }\end{array}$ & $20.5(18.1-22.9)$ & $66.3(64.6-69.1)$ & $46.2(43.8-49.1)$ & $17.2(15.7-19.5)$ \\
\hline & High school or above & $12.6(10.3-14.9)$ & $62.5(59.9-65.3)$ & $41.4(38.7-44.2)$ & $24.5(22.1-27.0)$ \\
\hline All & & $26.5(23.7-28.1)$ & $64.6(61.9-67.1)$ & $44.5(41.7-47.2)$ & $15.3(12.8-16.9)$ \\
\hline
\end{tabular}

Adjusted age and sex; control is defined as $\mathrm{BP}<140 / 90 \mathrm{mmHg}$

which would also result in uncontrolled hypertension when checked later [17]. (2) Primary care physicians in the stockraising region might have been less knowledgeable or experienced compared with tertiary hospital outpatients in urban settings. Furthermore, the village doctors region might have been entrenched in traditional prescription habits and lack knowledge or willingness to follow new guidelines due to obstacles in information exchange [17]. Therefore, current findings may highlight the need for developing a region-targeted hypertension education program to coordinate the efforts of detection, prevention, and treatment of hypertension in this region. In addition, considering the limited availability of antihypertensive agents and the limited affordability of locals, especially of nomads, exploring and promoting simplified antihypertensive algorithms might be the cost-effective and easy-tomaster pathway for hypertension control.

Different prevalence and control of hypertension may also be attributable to different environmental exposures, ethnicspecific genetic susceptibility, and the interactions between gene and environment $[18,19]$. Xinjiang is a multiethnicitypopulated area. Kazakh and Uygur population have a mixture of $40 \%$ Asian ancestry and 60\% European ancestry [20] and also have higher intake of salt and animal fat and proteins $[21,22]$, and stock-raising regions are characterized by few outdoor activities during long and cold winter, which may lead to a higher prevalence of hypertension than Han ethnicity. In addition, it is observed that Kazakh subjects, mostly leading nomadic or seminomadic life, have higher lifestylerelated risk factors for hypertension such as alcohol intake, cigarette consumption, and obesity and poor health awareness and poor health facility access due to higher illiteracy rates, language communication barriers, and mobile life [23], which may also contribute to their higher prevalence of hypertension and low control rates. In order to improve the prevention and control of hypertension in the stock-raising setting and Kazakhs, it is important to strengthen the promotion of health knowledge such as smoking cessation, alcohol restriction, and weight loss and to enhance primary care service. More importantly, Kazakh ethnicity is currently living in Kazakhstan, Uzbekistan, Russia, China, and Turkey, who still share lifestyle, dietary habits, and burden of hypertension [24]. Although a few studies reported higher prevalence of hypertension in this ethnic group [24], there are few epidemiological data on its associated factors. Therefore, results of the current study could extend to this specific population from other regions in terms of prevention of hypertension.

The present study highlights that alcohol intake, cigarette smoking, and obesity may increase the risk of hypertension in Xinjiang residents, consistent with previous literatures [25-28]. Most importantly, alcohol intake, compared to nondrinkers, was significantly related to increased prevalence of hypertension by 3.9 folds. Therefore, control of alcohol intake should be implemented as dominant (effective) measures or strategies to promote the prevention and management of hypertension in the setting.

Current analysis is strengthened by study subjects covering one third of locals and by their diversity in regions, age, sex, and ethnic groups, which makes them highly representative of locals [29]. However, this study contains some limitations. First, the population in this region prefer high salt intake, and we failed to collect salt intake of the population. Nonetheless, a survey is being conducted currently on salt intake in local population. Second, the cross-sectional nature of the study does 
TABLE 3: Factors associated with hypertension from multiple logistic regression.

\begin{tabular}{|c|c|c|c|c|c|}
\hline Variables & Stratification & $\begin{array}{c}\text { Prevalence OR }(95 \% \\
\mathrm{CI})\end{array}$ & $\begin{array}{c}\text { Awareness OR }(95 \% \\
\text { CI) }\end{array}$ & $\begin{array}{l}\text { Treatment OR }(95 \% \\
\text { CI) }\end{array}$ & $\begin{array}{c}\text { Control OR }(95 \% \\
\text { CI) }\end{array}$ \\
\hline \multirow{2}{*}{ Gender } & Women & 1 (reference) & 1 (reference) & 1 (reference) & 1 (reference) \\
\hline & Men & $0.88(0.82-0.94)$ & $0.77(0.67-0.87)$ & $0.80(0.72-0.88)$ & $0.94(0.83-1.06)$ \\
\hline \multirow{3}{*}{ Age } & $18-44$ & 1 (reference) & 1 (reference) & 1 (reference) & 1 (reference) \\
\hline & $45-60$ & $4.95(4.61-5.31)$ & $4.71(4.10-5.43)$ & $4.15(3.57-4.82)$ & $3.08(2.44-3.90)$ \\
\hline & $60+$ & $12.29(11.28-13.38)$ & $11.55(9.82-13.57)$ & $8.26(7.05-9.68)$ & $3.90(3.07-4.94)$ \\
\hline \multirow{3}{*}{ Regions } & Agriculture & 1 (reference) & 1 (reference) & 1 (reference) & 1 (reference) \\
\hline & Stock-raising & $0.96(0.79-1.23)$ & $2.38(2.04-2.78)$ & $1.98(1.74-2.25)$ & $0.98(0.83-1.15)$ \\
\hline & Urban & $1.63(1.47-1.79)$ & $1.03(0.86-1.23)$ & $1.05(0.89-1.25)$ & $0.82(0.66-1.03)$ \\
\hline \multirow{5}{*}{ Ethnicity } & Han & 1 (reference) & 1 (reference) & 1 (reference) & 1 (reference) \\
\hline & Kazakh & $1.68(1.57-1.80)$ & $0.90(0.88-1.12)$ & $1.10(0.99-1.23)$ & $0.58(0.51-0.67)$ \\
\hline & Uighur & $0.94(0.76-1.16)$ & $1.17(0.77-1.79)$ & $1.16(0.81-1.65)$ & $1.23(0.84-1.80)$ \\
\hline & Mongolian & $1.42(1.23-1.64)$ & $1.01(0.77-1.32)$ & $1.08(0.86-1.36)$ & $0.78(0.59-1.03)$ \\
\hline & Other & $0.78(0.66-0.93)$ & $0.81(0.59-1.13)$ & $1.12(0.83-1.50)$ & $1.03(0.74-1.44)$ \\
\hline \multirow{3}{*}{$\begin{array}{l}\text { Education } \\
\text { status }\end{array}$} & Primary and lower & 1 (reference) & 1 (reference) & 1 (reference) & 1 (reference) \\
\hline & Elementary middle school & $0.62(0.58-0.66)$ & $1.20(1.07-1.36)$ & $0.98(0.89-1.10)$ & $1.29(1.13-1.47)$ \\
\hline & High school or above & $0.33(0.29-0.39)$ & $0.87(0.63-1.20)$ & $0.74(0.54-1.02)$ & $1.38(0.96-2.00)$ \\
\hline \multirow[b]{2}{*}{ Occupation } & Agriculture or husbandry & 1 (reference) & 1 (reference) & 1 (reference) & 1 (reference) \\
\hline & $\begin{array}{c}\text { Nonagriculture or } \\
\text { nonhusbandry }\end{array}$ & $2.24(2.07-2.43)$ & $1.08(0.94-1.23)$ & $1.01(0.89-1.13)$ & $0.64(0.54-0.75)$ \\
\hline \multirow{3}{*}{ Marital status } & Single & 1 (reference) & 1 (reference) & 1 (reference) & 1 (reference) \\
\hline & Married & $2.55(2.14-3.03)$ & $1.99(1.30-3.07)$ & $2.76(1.57-4.85)$ & $1.05(0.55-1.99)$ \\
\hline & Divorced & $3.55(2.84-4.44)$ & $2.82(1.74-4.59)$ & $3.14(1.74-5.67)$ & $1.65(0.85-3.23)$ \\
\hline \multirow{3}{*}{ BMI (WGOC) } & Normal & 1 (reference) & 1 (reference) & 1 (reference) & 1 (reference) \\
\hline & Overweight & $1.30(1.20-1.41)$ & $1.43(1.23-1.65)$ & $1.39(1.22-1.59)$ & $1.23(1.04-1.46)$ \\
\hline & Obesity & $1.94(1.75-2.15)$ & $2.73(2.27-3.27)$ & $1.20(1.70-2.34)$ & $1.44(1.17-1.77)$ \\
\hline \multirow{3}{*}{ BMI (WHO) } & Normal & 1 (reference) & 1 (reference) & 1 (reference) & 1 (reference) \\
\hline & Overweight & $1.36(1.27-1.46)$ & $1.38(1.22-1.57)$ & $1.20(1.07-1.34)$ & $1.15(0.99-1.33)$ \\
\hline & Obesity & $2.11(1.87-2.37)$ & $3.17(2.57-3.92)$ & $1.93(1.63-2.29)$ & $1.45(1.18-1.79)$ \\
\hline \multirow{2}{*}{ WC (WGOC) } & Normal & 1 (reference) & 1 (reference) & 1 (reference) & 1 (reference) \\
\hline & Abdominal obesity & $1.30(1.21-1.41)$ & $0.80(0.70-0.93)$ & $0.85(0.75-0.97)$ & $0.89(0.75-1.05)$ \\
\hline \multirow{2}{*}{ WC (WHO) } & Normal & 1 (reference) & 1 (reference) & 1 (reference) & 1 (reference) \\
\hline & Abdominal obesity & $1.32(1.22-1.41)$ & $0.996(0.87-1.14)$ & $1.03(0.92-1.16)$ & $0.96(0.83-1.12)$ \\
\hline \multirow{2}{*}{$\begin{array}{l}\text { Cigarette } \\
\text { smoking }\end{array}$} & No & 1 (reference) & 1 (reference) & 1 (reference) & 1 (reference) \\
\hline & Yes & $2.49(2.20-2.81)$ & $4.88(3.66-6.50)$ & $2.64(1.94-3.58)$ & $1.79(1.23-2.60)$ \\
\hline \multirow{2}{*}{$\begin{array}{l}\text { Alcohol } \\
\text { drinking }\end{array}$} & No & 1 (reference) & 1 (reference) & 1 (reference) & 1 (reference) \\
\hline & Yes & $4.90(4.33-5.53)$ & $11.37(8.58-15.07)$ & $8.04(5.84-11.05)$ & $2.89(1.98-4.23)$ \\
\hline
\end{tabular}

BMI: body mass index; DBP, diastolic blood pressure; SBP, systolic blood pressure; SD, standard deviation; WC, waist circumference; WGOC: Working Group on Obesity in China.; OR: odd ratio; CI: confidence interval.

not allow to get a cause-and-effect relationship between hypertension and related factors. However, it is also the common way of finding problems and providing clues for prevention. Third, this study did not investigate some information such as socioeconomic status and family income level, which may be related to the control of hypertension.

\section{Conclusions}

Existing disparities in hypertension and its management among regions and ethnic groups suggest its inadequate screening and treatment, especially in stock-raising regions and Kazakh populations. Control of alcohol intake, cigarette consumption, and weight and enhancement of primary care service should be at high priority of health promotion. Current results could also extend to Belt and Road countries such as Kazakhstan.

\section{Data Availability}

Materials included in the manuscript, including all relevant raw data, will be made freely available to any researchers who wish to use them for noncommercial purposes, while preserving any necessary confidentiality and anonymity.

\section{Conflicts of Interest}

The authors declare that they have no conflicts of interest.

\section{Authors' Contributions}

NL designed the study. MH, XY, GD, MC, and KZ collected the data. LW and XY performed the analyses with guidance from NL. LW drafted the manuscript with help from NL and $\mathrm{MH}$. NM, MW, JH, and DZ revised the manuscript and made valuable contributions to the manuscript and its 
conclusions. All authors read and approved the final manuscript to be published and agreed to be accountable for all aspects of the work. Lin Wang and Nanfang Li contributed equally to this work.

\section{Acknowledgments}

The authors thank all the study participants for the great support and thank volunteers for providing great help. The authors also thank county leaders and leaders of health, education, finance, and science and technology bureau for their greatest support on this program and making the hypertension as the priority and for establishing a committee to conduct and oversee the screening project. Finally, the authors thank the Ministry of Science and Technology of the People's Republic of China and the Department of Science and Technology of Xinjiang Uygur Autonomous Region of China for funding the project. This study was supported by a grant from The Key Research and Development Project of Xinjiang Uygur Autonomous Region China (grant no. 2017B03015) and the Ministry of Science and Technology of the People's Republic of China (grant no. 2013GS650101).

\section{Supplementary Materials}

Factors associated with prevalence, awareness, treatment, and control of hypertension from multiple logistic regressions: Supplementary Figure 2: hypertension, Supplementary Figure 3: awareness, Supplementary Figure 4: treatment, Supplementary Figure 5: control. (Supplementary Materials)

\section{References}

[1] C. M. Lawes, S. V. Hoorn, and A. Rodgers, "Global burden of blood-pressure-related disease, 2001," The Lancet, vol. 371, no. 9623, pp. 1513-1518, 2008.

[2] J. He, D. Gu, J. Chen et al., "Premature deaths attributable to blood pressure in China: a prospective cohort study," The Lancet, vol. 374, no. 9703, pp. 1765-1772, 2009.

[3] W. Wang, B. Jiang, H. Sun et al., "Prevalence, incidence, and mortality of stroke in China," Circulation, vol. 135, no. 8, pp. 759-771, 2017.

[4] V. L. Feigin, G. A. Roth, M. Naghavi et al., "Global burden of stroke and risk factors in 188 countries, during 1990-2013: a systematic analysis for the global burden of disease study 2013," Lancet Neurology, vol. 15, no. 9, pp. 913-924, 2016.

[5] Y.-T. Wang, D. Adi, Z.-X. Yu et al., "The burden and correlates of hypertension among Chinese rural population in Han, Uygur, and Kazak: a cross-sectional study," Journal of the American Society of Hypertension, vol. 11, no. 11, pp. 737-745, 2017.

[6] W. Li, H. Gu, K. K. Teo et al., "Hypertension prevalence, awareness, treatment, and control in 115 rural and urban communities involving 47,000 people from China," Journal of Hypertension, vol. 34, no. 1, pp. 39-46, 2016.

[7] C. M. Chen, W. H. Zhao, Z. X. Yang, Y. Zhai, Y. F. Wu, and L. Z. Kong, "The role of dietary factors in chronic disease control in China," Zhonghua Liu Xing Bing Xue Za Zhi, vol. 27, no. 9, pp. 739-743, 2006.

[8] I. S. Krishnadath, V. W. Jaddoe, and L. M. Nahar-van Venrooij, "Ethnic differences in prevalence and risk factors for hypertension in the suriname health study: a cross sectional population study," Population Health Metrics, vol. 14, no. 1, p. 33, 2016.

[9] G. K. Singh, M. Siahpush, and L. Liu, "Racial/ethnic, nativity, and sociodemographic disparities in maternal hypertension in the United States, 2014-2015," International Journal of Hypertension, vol. 2018, Article ID 7897189, 14 pages, 2018.

[10] Z. Wang, Z. Chen, L. Zhang et al., "Status of hypertension in China," Circulation, vol. 137, no. 22, pp. 2344-2356, 2018.

[11] National Bureau of Statistics of China, February 2019, http:// www.stats.gov.cn/tjsj/tjbz/tjyqhdmhcxhfdm/.

[12] S. S. Yoon, M. D. Carroll, and C. D. Fryar, "Hypertension prevalence and control among adults: United States, 20112014," NCHS Data Brief, vol. 220, pp. 1-8, 2015.

[13] C. Diederichs and H. Neuhauser, "Regional variations in hypertension prevalence and management in Germany," Journal of Hypertension, vol. 32, no. 7, pp. 1405-1414, 2014.

[14] F. Liu, Y. T. Ma, Y. N. Yang et al., "Current status of primary hypertension in Xinjiang: an epidemiological study of Han, Uygur and Hazakh populations," Zhonghua Yi Xue Za Zhi, vol. 90, no. 46, pp. 3259-3263, 2010.

[15] L. Cong, J. Q. Zhan, L. Yang et al., "Overweight and obesity among low-income Muslim Uyghur women in far western China: correlations of body mass index with blood lipids and implications in preventive public health," PLoS One, vol. 9, no. 2, Article ID e90262, 2014.

[16] W. J. Zhang, F. Li, Y. H. Wang et al., "The case for semimandatory HPV vaccination in China," Nature Biotechnology, vol. 31, no. 7, pp. 590-591, 2013.

[17] Z. Wang, X. Wang, Z. Chen et al., "Hypertension control in community health centers across China: analysis of antihypertensive drug treatment patterns," American Journal of Hypertension, vol. 27, no. 2, pp. 252-259, 2014.

[18] T. Hasi, L. Hao, L. Yang, and X. L. Su, "Acetaldehyde dehydrogenase 2 SNP rs671 and susceptibility to essential hypertension in Mongolians: a case control study," Genetics and Molecular Research, vol. 10, no. 1, pp. 537-543, 2011.

[19] M. L. Black, W. Wang, and A. H. Bittles, "A genome-based study of the muslim Hui community and the Han population of liaoning province, PR China," Human Biology, vol. 73, no. 6, pp. 801-813, 2001.

[20] S. Xu, W. Huang, J. Qian, and L. Jin, "Analysis of genomic admixture in Uyghur and its implication in mapping strategy," The American Journal of Human Genetics, vol. 82, no. 4, pp. 883-894, 2008.

[21] W. Han, Y. Hu, Y. Tang et al., "Relationship between urinary sodium with blood pressure and hypertension among a $\mathrm{Ka}$ zakh community population in Xinjiang, China," Journal of Human Hypertension, vol. 31, no. 5, pp. 333-340, 2017.

[22] F. Zhai, Y. He, Z. Wang et al., "Status and characteristic of dietary intake of 12 minority nationalities in China," Wei Sheng Yan Jiu, vol. 36, no. 5, pp. 539-541, 2007.

[23] X. Wu, X. Duan, D. Gu, J. Hao, S. Tao, and D. Fan, "Prevalence of hypertension and its trends in Chinese populations," International Journal of Cardiology, vol. 52, no. 1, pp. 39-44, 1995.

[24] A. Supiyev, A. Kossumov, L. Utepova, T. Nurgozhin, Z. Zhumadilov, and M. Bobak, "Prevalence, awareness, treatment and control of arterial hypertension in Astana, Kazakhstan: a cross-sectional study," Public Health, vol. 129, no. 7, pp. 948-953, 2015.

[25] A. Corbatón-Anchuelo, M. T. Martínez-Larrad, N. Del PradoGonzález et al., "Prevalence, treatment, and associated factors of hypertension in Spain: a comparative study between 
populations," International Journal of Hypertension, vol. 2018, Article ID 4851512, 11 pages, 2018.

[26] N. Li, H. Wang, Z. Yan et al., "Ethnic disparities in the clustering of risk factors for cardiovascular disease among the Kazakh, Uygur, Mongolian and Han populations of Xinjiang: a cross-sectional study," BMC Public Health, vol. 12, no. 1, pp. 499-504, 2012.

[27] D. Li, J. Lv, F. Liu et al., "Hypertension burden and control in mainland China: analysis of nationwide data 2003-2012," International Journal of Cardiology, vol. 184, pp. 637-644, 2015.

[28] Y. Wu, R. Huxley, L. Li et al., "Prevalence, awareness, treatment, and control of hypertension in China," Circulation, vol. 118, no. 25, pp. 2679-2686, 2008.

[29] R. W. Yeh, S. Sidney, M. Chandra, M. Sorel, J. V. Selby, and A. S. Go, "Population trends in the incidence and outcomes of acute myocardial infarction," New England Journal of Medicine, vol. 362, no. 23, pp. 2155-2165, 2010. 


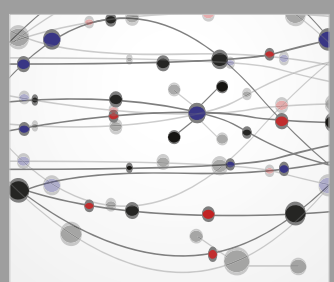

The Scientific World Journal
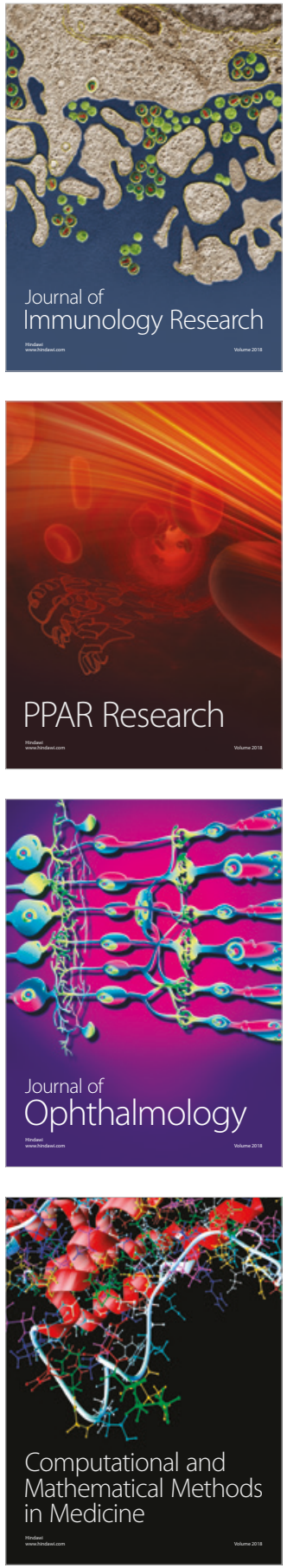

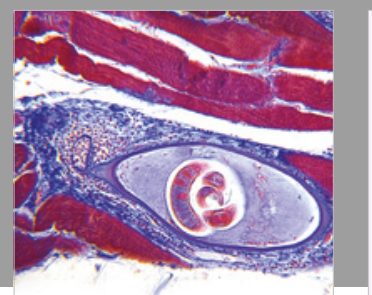

Gastroenterology Research and Practice

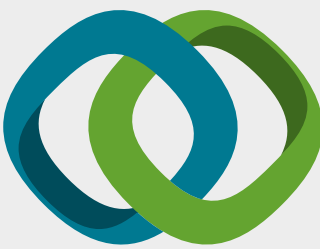

\section{Hindawi}

Submit your manuscripts at

www.hindawi.com
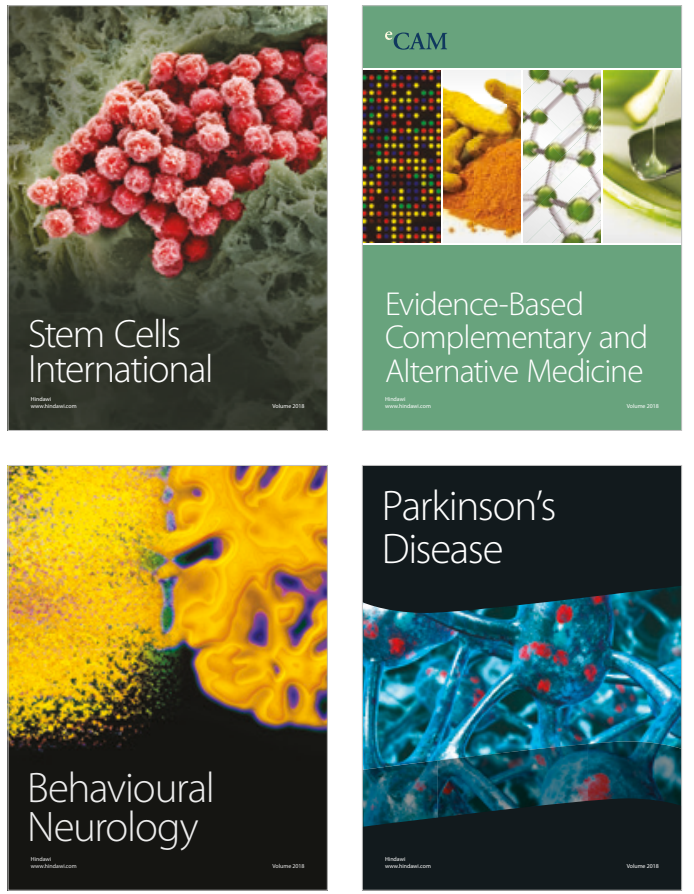

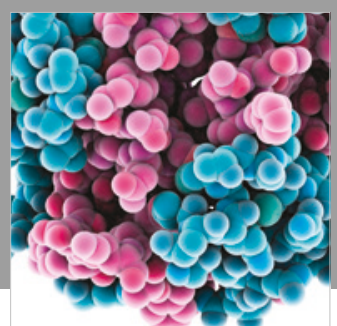

ournal of

Diabetes Research

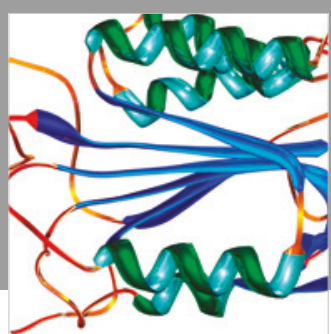

Disease Markers
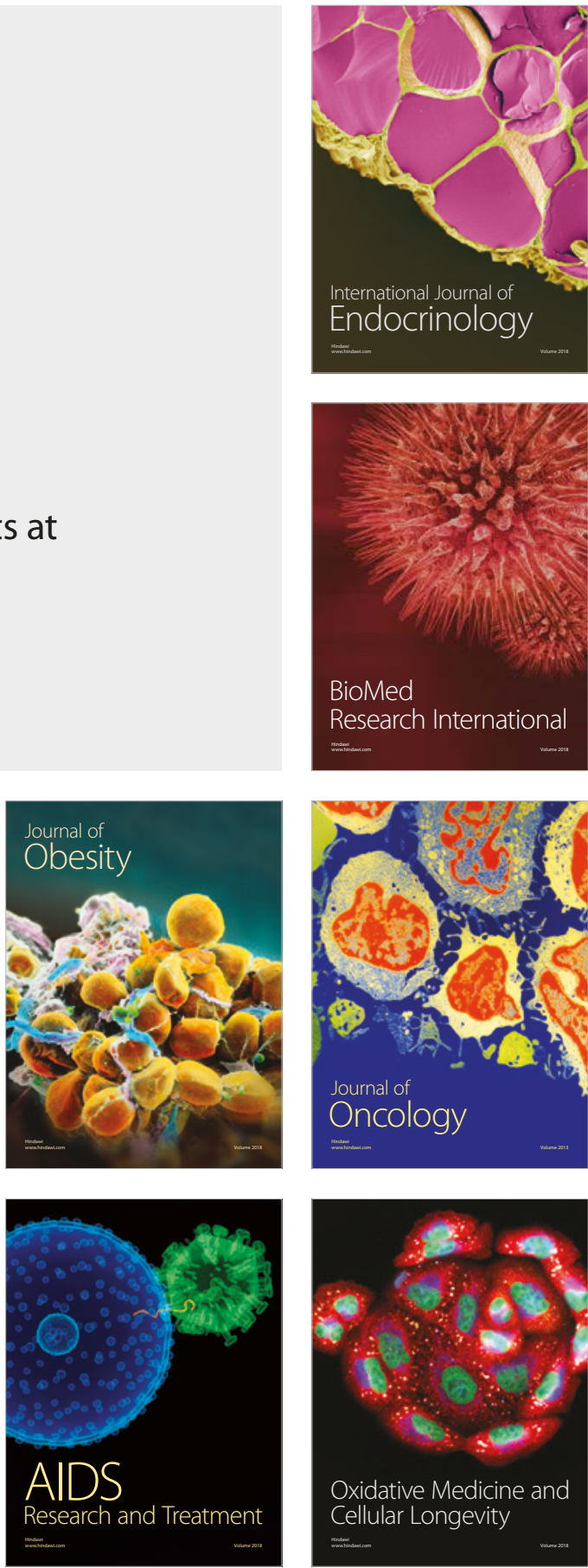